\title{
Comparison of Circumferential Pulmonary Vein Isolation and Antiarrhythmic Drug Therapy in Patients with Atrial Fibrillation
}

Yanmin $\mathrm{Xu} \cdot$ Deepak Sharma $\cdot$ Fawang Du

Guangping Li $\cdot$ Gang Xu

To view enhanced content go to www.cardiologytherapy-open.com

Received: June 28, 2012 / Published online: September 8, 2012

(C) The Author(s) 2012. This article is published with open access at Springerlink.com

\section{ABSTRACT}

Introduction: The aim of this study was to evaluate quality of life after circumferential pulmonary vein isolation (CPVI) compared with antiarrhythmic drug therapy (ADT) in treating atrial fibrillation (AF). CPVI is now a common therapy in $\mathrm{AF}$, but few studies have focused on the effect of CPVI on quality of life. Methods: A total of 123 AF patients were followed prospectively. Quality of life was evaluated comparing CPVI with ADT as a second-line treatment for patients with AF. The Medical Outcomes Study Short Form (SF)36 health surveys were conducted to establish a

Y. Xu (ه) • F. Du · G. Li · G. Xu

Cardiovascular Institute of Tianjin, 23 Ping Jiang

Road, He Xi District, Tianjin, China

e-mail: xuyanmin@eyou.com

D. Sharma

Tianjin Medical University, Tianjin, China baseline score before initiation and again at 6 months after the intervention.

Results: Mean follow-up duration was $12.7 \pm$ 4.3 months. Of 123 patients enrolled, 66 were randomized to receive CPVI and 57 to ADT alone. At the 6-month follow-up, 13 (22.8\%) patients in the ADT group and $41(62.1 \%)$ patients in the CPVI group had no recurrence of AF. The SF-36 scales were significantly higher in the CPVI than in the ADT group, as were the physical component summary scores $(269.3 \pm 58.6$ vs. $234.9 \pm 66.9)$ and mental component summary scores $(273.6 \pm 69.4$ vs. $234.1 \pm 44.7)$. Quality of life was significantly higher in the CPVI group (except for body pain).

Conclusion: In patients with AF, CPVI has superiority over ADT with regards to the maintenance of sinus rhythm and improvements in quality of life.

Keywords: Circumferential pulmonary vein isolation; Antiarrhythmic drug therapy; Atrial fibrillation; Quality of life

\section{INTRODUCTION}

Atrial fibrillation (AF) is the most common sustained cardiac arrhythmia. The prevalence 
has been increasing with the aging population and the growing number of individuals who survive with chronic cardiovascular diseases. AF increases the risk of stroke and other embolic events, and has been associated with diminished functional status and heart failure symptoms of diastolic dysfunction with the development of dilated cardiomyopathy. It considerably impairs the patients' quality of life (QoL). The technique of circumferential pulmonary vein isolation (CPVI) has undergone rapid evolution and has emerged as an important strategy in the treatment of patients with AF, although its effect on QoL has not been fully characterized. The aim of the present study was to evaluate effect on QoL score in patients with AF after treatment with CPVI compared with antiarrhythmic drug therapy (ADT).

\section{MATERIALS AND METHODS}

\section{Patients}

The study included 123 patients with AF, randomized to CPVI $(n=66)$ or ADT alone $(n=57)$. All patients were followed-up for 6 months after the intervention.

\section{QoL Assessment}

QoL was assessed using the Medical Outcomes Study Short Form-36 (SF-36) health survey questionnaire [1]. The SF-36 assesses eight specific QoL domains. It contains items to assess physical health (general health perception, physical functioning, role limitations due to physical problems, and bodily pain) and mental health (social functioning, role limitations due to emotional problems, mental health, and vitality). The total score from the eight scales can range from 0 to 100 , with higher scores representing better functioning and QoL than lower scores.

\section{CPVI}

The right internal jugular vein or subclavian vein was punctured while patients were under local anesthesia (lidocaine). An electrode catheter was introduced into the coronary sinus to record left atrial electrical activity and pacing. The intra-atrial septum was punctured under X-ray guidance projected into a SWARTZ L1 and R0 expansion scabbard along the sheath pipe into the ablation catheter infused with a cold saline catheter (St. Jude, USA) and LASSO catheter (St. Jude, USA). Under X-ray guidance and the EnSite3000 noncontact mapping system, three-dimensional (3D) electroanatomic maps were constructed. The left and right pulmonary veins were encircled, with additional lines in the posterior left atrium or roof and along the mitral isthmus for those who had atrial flutter. Contiguous applications of radiofrequency energy were delivered at a target temperature of $50-60^{\circ} \mathrm{C}$ and a maximal power output of $40-50 \mathrm{~W}$. The endpoint of ablation was an $80 \%$ reduction in the amplitude of the electrogram or a total of $40 \mathrm{~s}$ of energy application. Additional ablation was performed in the outer pulmonary veins, where the local electrogram amplitude exceeded $0.2 \mathrm{mV}$. If $\mathrm{AF}$ was still present at the end of circumferential pulmonary vein ablation, either amiodarone or transthoracic cardioversion was used to restore sinus rhythm.

\section{Follow-Up and Study Objectives}

All patients were systematically followed up for 6 months after the intervention, with the following parametric data obtained: 12-lead 
electrocardiography (ECG), echocardiography, and 24-h Holter recording at baseline and 1, 3, and 6 months. Additional 12-lead ECG or a Holter measurement was encouraged when patients experienced palpitations. QoL was assessed using the SF-36 survey at baseline and again at 6 months after the intervention. Episodes were qualified as $\mathrm{AF}$, if they lasted at least $3 \mathrm{~min}$ and were documented by ECG/ Holter or reported by the patient as AF, even in the absence of ECG confirmation.

\section{Statistical Analysis}

Analysis was carried out using SAS 16.0 statistical software package. Continuous variables were summarized by mean \pm standard deviation or the median and interquartile range (25th and 75th percentiles), and were compared using $t$-tests or Wilcoxon rank sum test. Categorical variables were represented by frequencies and percentages, and were compared using $\chi^{2}$ tests. Differences were considered significant at $P<0.05$.

\section{RESULTS}

\section{Clinical Characteristics}

Clinical characteristics of 123 enrolled patients are shown in Table 1. Sixty-six patients underwent CPVI (45 males and 21 females with the mean age of $61.5 \pm 10.1$ years). Fiftyseven patients received ADT (35 males and 22 females with the mean age of $60.9 \pm$ 13.7 years). The baseline characteristics were comparable, with no significant differences between two groups (e.g., age, gender, paroxysmal AF or persistent AF, coronary artery disease, hypertension, and valvular heart disease; Tables 1, 2).

\section{QoL at Baseline and at Follow-up}

A total of 123 patients were prospectively followed up for 6 months. At the 6-month follow-up $13(22.8 \%)$ patients in the ADT group and $41(62.1 \%)$ patients in the CPVI group had no recurrence of AF. At baseline, there were no significant differences in QoL between the ADT and CPVI groups. Table 3 shows the changes in QoL from baseline to the 6-month follow-up assessment for the SF-36 scales pertaining to physical and mental health in the CPVI group. For all scales the observation was statistically significant different in the CPVI group at baseline vs. 6 months (Table 3), For seven of eight scales (except for body pain), the observation was statistically significant at baseline vs. 6 months in the CPVI group. The 6-month physical component summary (PCS) and mental component summary (MCS) scores

Table 1 Baseline patient characteristics between circumferential pulmonary vein isolation (CPVI) and antiarrhythmic drug therapy (ADT) group

\begin{tabular}{lllllll}
\hline Group & Age (years) & Total AF duration (years) & \multicolumn{2}{l}{ Echocardiography } & \multicolumn{2}{c}{ Mean rate } \\
\cline { 5 - 7 } & & & LA ( mm) & LV (mm) & EF & \\
\hline CPVI $(n=66)$ & $61.5 \pm 10.1$ & $6.2 \pm 5.6$ & $39.2 \pm 5.6$ & $46.4 \pm 4.9$ & $58.5 \pm 7.4$ & $75.9 \pm 19.3$ \\
ADT $(n=57)$ & $60.9 \pm 13.7$ & $4.6 \pm 6.2$ & $39.1 \pm 5.9$ & $47.5 \pm 6.4$ & $58.1 \pm 6.2$ & $74.1 \pm 20.1$ \\
$t$-value & 0.27 & 1.51 & 0.12 & 1.04 & 0.36 & 0.51 \\
$P$-value & 0.79 & 0.14 & 0.91 & 0.91 & 0.30 & 0.61 \\
\hline
\end{tabular}

$A F$ atrial fibrillation, $E F$ ejection fraction, $L A$ left arterial, $L V$ left ventricular 
Table 2 Baseline patient characteristics between circumferential pulmonary vein isolation (CPVI) and antiarrhythmic drug therapy (ADT) group

\begin{tabular}{|c|c|c|c|c|c|c|c|c|c|}
\hline & \multirow{2}{*}{$\begin{array}{l}\text { Male, } \\
n(\%)\end{array}$} & \multirow{2}{*}{$\begin{array}{l}\text { Hypertension, } \\
n(\%)\end{array}$} & \multirow{2}{*}{$\begin{array}{l}\text { Diabetes } \\
\text { mellitus, } \\
n(\%)\end{array}$} & \multirow{2}{*}{$\begin{array}{l}\text { Stroke, } \\
n(\%)\end{array}$} & \multicolumn{2}{|l|}{ Type of AF } & \multicolumn{3}{|c|}{ Underlying disease } \\
\hline & & & & & $\begin{array}{l}\text { Paroxysmal, } \\
n(\%)\end{array}$ & $\begin{array}{l}\text { Persistent, } \\
n(\%)\end{array}$ & $\begin{array}{l}\text { CHD, } \\
n(\%)\end{array}$ & $\begin{array}{l}\text { HC, } \\
n(\%)\end{array}$ & $\begin{array}{l}\text { VHD, } \\
n(\%)\end{array}$ \\
\hline CPVI & $45(68.1)$ & $27(40.9)$ & $8(12.1)$ & $5(7.6)$ & $60(90.9)$ & $6(9.1)$ & $21(37.5)$ & $3(4.5)$ & $3(4.5)$ \\
\hline ADT & $35(61.4)$ & $20(35.1)$ & $13(22.8)$ & $6(10.5)$ & $50(87.7)$ & $7(12.3)$ & $28(49.1)$ & $4(7.0)$ & $2(3.5)$ \\
\hline$\chi^{2}$-value & 0.62 & 0.44 & 0.47 & 0.33 & 0.33 & & 4.84 & & \\
\hline$P$-value & 0.43 & 0.51 & 0.12 & 0.57 & 0.57 & & 0.39 & & \\
\hline
\end{tabular}

$A F$ atrial fibrilation, $C H D$ coronary heart disease, $H C$ hypertensive cardiopathy, $V H D$ valvular heart disease

Table 3 The mean changes from baseline to 6-months for the SF-36 scales

\begin{tabular}{|c|c|c|c|c|c|c|}
\hline & \multicolumn{2}{|l|}{ CPVI } & \multirow[t]{2}{*}{$P$} & \multicolumn{2}{|l|}{ ADT } & \multirow[t]{2}{*}{$P$} \\
\hline & $\begin{array}{l}\text { Baseline } \\
\text { Mean } \pm \text { SD }\end{array}$ & $\begin{array}{l}\text { 6-months } \\
\text { Mean } \pm \text { SD }\end{array}$ & & $\begin{array}{l}\text { Baseline } \\
\text { Mean } \pm \text { SD }\end{array}$ & $\begin{array}{l}\text { 6-months } \\
\text { Mean } \pm \text { SD }\end{array}$ & \\
\hline $\mathrm{PF}$ & $67.1 \pm 17.9$ & $76.0 \pm 17.5$ & 0.005 & $62.1 \pm 26.3$ & $65.1 \pm 20.4$ & 0.494 \\
\hline $\mathrm{RP}$ & $46.9 \pm 17.6$ & $58.0 \pm 22.9$ & 0.002 & $42.5 \pm 20.6$ & $48.9 \pm 26.9$ & 0.174 \\
\hline $\mathrm{BP}$ & $58.6 \pm 24.0$ & $69.3 \pm 21.2$ & 0.007 & $60.6 \pm 20.3$ & $66.8 \pm 22.2$ & 0.120 \\
\hline $\mathrm{GH}$ & $48.2 \pm 20.7$ & $66.0 \pm 19.9$ & $<0.001$ & $42.9 \pm 25.5$ & $52.2 \pm 26.8$ & 0.023 \\
\hline VT & $60.9 \pm 16.5$ & $70.8 \pm 20.3$ & 0.003 & $57.4 \pm 17.5$ & $62.8 \pm 13.2$ & 0.062 \\
\hline SF & $56.4 \pm 21.1$ & $70.1 \pm 24.3$ & 0.001 & $53.3 \pm 17.3$ & $60.5 \pm 17.7$ & 0.030 \\
\hline $\mathrm{MH}$ & $60.8 \pm 15.9$ & $72.4 \pm 16.4$ & $<0.001$ & $60.1 \pm 11.2$ & $62.3 \pm 12.2$ & 0.324 \\
\hline $\mathrm{RE}$ & $50.0 \pm 25.0$ & $60.4 \pm 26.1$ & 0.021 & $42.7 \pm 25.8$ & $48.4 \pm 27.4$ & 0.255 \\
\hline PCS & $220.8 \pm 54.6$ & $269.3 \pm 58.6$ & $<0.001$ & $208.2 \pm 64.9$ & $234.9 \pm 66.9$ & 0.033 \\
\hline MCS & $228.1 \pm 54.3$ & $273.6 \pm 69.4$ & $<0.001$ & $213.5 \pm 44.5$ & $234.1 \pm 44.7$ & 0.015 \\
\hline
\end{tabular}

$A D T$ antiarrhythmic drug therapy, $B P$ bodily pain, $C P V I$ circumferential pulmonary vein isolation, $G H$ general health perception, $M C S$ mental component summary, $M H$ mental health, $P C S$ physical component summary, $P F$ physical functioning, $R E$ role limitations due to emotional problems, $R P$ role limitations due to physical problems, $V T$ vitality, $S F$ social functioning

were increased significantly in the CPVI group to $269.3 \pm 58.6$ and $273.6 \pm 69.4$, respectively (within-group $P<0.001$ for both; Table 3 ). In the ADT group, the PCS and MCS scores also increased at 6 months to $234.9 \pm 66.9$ and $234.1 \pm 44.7$, respectively (within-group $P<$ 0.05 for both; Table 3). However, at 6 months, SF-36 scales were significantly higher in the
CPVI group than in the ADT group, as were the PCS scores $(269.3 \pm 58.6$ vs. $234.9 \pm 66.9$; $P<0.05)$ and MCS scores $(273.6 \pm 69.4$ vs. $234.1 \pm 44.7 ; P<0.001$; Table 4$)$.

Patients in the CPVI group were further evaluated based on whether they had AF recurrence. Among patients who had no AF recurrence, the difference in all eight SF-36 scale 
Table 4 The mean changes of each group for the SF-36 scales

\begin{tabular}{|c|c|c|c|}
\hline & $\begin{array}{l}\text { CPVI } \\
\text { Mean } \pm \text { SD }\end{array}$ & $\begin{array}{l}\text { ADT } \\
\text { Mean } \pm \text { SD }\end{array}$ & $P$ value \\
\hline $\mathrm{PF}$ & $76.0 \pm 17.5$ & $65.1 \pm 20.4$ & 0.002 \\
\hline $\mathrm{RP}$ & $58.0 \pm 22.9$ & $48.9 \pm 26.9$ & 0.041 \\
\hline BP & $69.3 \pm 21.2$ & $66.8 \pm 22.2$ & 0.528 \\
\hline $\mathrm{GH}$ & $66.0 \pm 19.9$ & $52.2 \pm 26.8$ & 0.007 \\
\hline VT & $70.8 \pm 20.3$ & $62.8 \pm 13.2$ & 0.010 \\
\hline SF & $70.1 \pm 24.3$ & $60.5 \pm 17.7$ & 0.013 \\
\hline $\mathrm{MH}$ & $72.4 \pm 16.4$ & $62.3 \pm 12.2$ & $<0.001$ \\
\hline RE & $60.4 \pm 26.1$ & $48.4 \pm 27.4$ & 0.015 \\
\hline PCS & $269.3 \pm 58.6$ & $234.9 \pm 66.9$ & 0.003 \\
\hline MCS & $273.6 \pm 69.4$ & $234.1 \pm 44.7$ & $<0.001$ \\
\hline
\end{tabular}

$A D T$ antiarrhythmic drug therapy, $B P$ bodily pain, $C P V I$ circumferential pulmonary vein isolation, $G H$ general health perception, $M C S$ mental component summary, $M H$ mental health, $P C S$ physical component summary, $P F$ physical functioning, $R E$ role limitations due to emotional problems, $R P$ role limitations due to physical problems, $V T$ vitality, $S F$ social functioning

measurements was statistically significant between the baseline and 6-month evaluations. Whereas the difference in all eight SF-36 scale measurements in patients with $\mathrm{AF}$ recurrence was statistically insignificant, except for the role limitations due to emotional problems.

\section{DISCUSSION}

$\mathrm{AF}$ is the most common chronic arrhythmia associated with an adverse prognosis. It is an independent risk factor for stroke, resulting in an approximate three- to fivefold excess risk [2]. Furthermore, the risks attributable to most stroke risk factors decline with advancing age [2]. AF causes disabling symptoms such as fatigue, dyspnea, and palpitations. As a result, the patient's QoL may be drastically reduced. The study showed that AF was associated with a 1.5-1.9-fold increased risk of mortality and was an independent predictor of mortality with stroke [3]. At present, more attention is focused on the research and treatment of $\mathrm{AF}$ in order to improve the QoL of patients with this disorder.

This study demonstrated that the SF-36 scales were significantly higher in patients treated with CPVI compared to ADT for all physical and mental health assessments except for body pain. The results of the present study indicate that compared with ADT, CPVI is more likely to maintain sinus rhythm, reduce dyspnea, palpitations, and stroke, and improve the QoL of AF patients.

In two previous trials, radiofrequency catheter ablation appeared superior to ADT treatment in improving symptoms and QoL [3, 4], which concurs with the present study. The results of a multicenter trial comparing catheter ablation with ADT in patients with symptomatic, paroxysmal AF refractory to one or more drugs showed the clear superiority of ablation on rhythm-related endpoints [5]. A different multicenter clinical trial that 
evaluated symptoms and QoL comparing catheter ablation with ADT as a second-line treatment for patients with paroxysmal AF concluded that ablation is superior to ADT at improving symptoms and QoL [6].

The results from a recent study by Wokhlu et al. [7] which enrolled 323 patients, showed that $72 \%$ of patients achieved AF elimination off ADT, $15 \%$ achieved AF control on ADT, and $13 \%$ had recurrent AF after 2 years of follow-up. The PCS and MCS scores also showed a noteworthy increase. The results of several trials have shown that radiofrequency catheter ablation is superior to ADT at maintaining sinus rhythm, primarily as a second-line treatment [8-11]. In the present study, after a mean follow-up of $12.7 \pm 4.3$ months, $22.8 \%$ and $62.1 \%$ of the ADT group and CPVI group, respectively, had no recurrence of AF. At 6 month, the PCS and MCS scores increased considerably in both the CPVI group and the ADT group. CPVI has a higher success rate and, thus, results in an elevated QoL.

The results of the Atrial Fibrillation Follow-up Investigation of Rhythm Management (AFFIRM) study [12] showed that there were no differences in survival or event rates in patients with $\mathrm{AF}$ randomized either to ventricular rate control or heart rhythm control. The QoL scores were comparable between the rate control and rhythm control interventions. In addition, QoL was similar with sinus rhythm versus AF control. Attempts to improve QoL by restoring sinus rhythm were usually unsuccessful [12]. A multicenter trial demonstrated that a routine strategy of heart rhythm control such as metoprolol or amiodarone does not reduce the rate of death from cardiovascular causes, as compared with a rate-control strategy [13]. In previous studies, the restoration and maintenance of sinus rhythm were often attempted with electrical cardioversion and
ADT. However, the favorable outcome acquired by restoring the sinus rhythm was counteracted by the increased risk of adverse effects from ADT. In this study, patients in the CPVI group were sorted into two groups based on AF recurrence: no AF recurrence group and AF recurrence group. In the no AF recurrence group, there was a significant difference in all eight SF-36 scales, but there was no statistically significant difference in the recurrence AF group, except for role limitations due to emotional problems. AF impaired QoL and was related to increased frequency and duration of disease and disease indexes. The present results show that restoration and maintenance of sinus rhythm can improve the QoL.

The effect of ADT on the QoL of patients with $\mathrm{AF}$ is still controversial $[8,12,13]$. A study by Dorian et al. [14] has suggested that QoL improvements were not significantly different among the groups randomized to amiodarone, sotalol, or propafenone, and this was especially true for patients in whom treatment prevented AF recurrence. The study found that general health perception, social functioning, and physical and mental health summary measures of the SF-36 scales improved significantly from baseline to 6 months. Thus, indicating the lack of superiority of ADT over ablation in patients with AF with regard to maintenance of sinus rhythm and improvement in QoL.

In summary, CPVI is superior to ADT in patients with AF regarding the maintenance of sinus rhythm and improvement in QoL, especially in patients in whom CPVI was successful.

\section{ACKNOWLEDGMENTS}

Dr. $\mathrm{Xu}$ is the guarantor for this article, and takes responsibility for the integrity of the work as a whole. 
Conflict of interest. The authors have no conflicts of interest.

Open Access. This article is distributed under the terms of the Creative Commons Attribution Noncommercial License which permits any noncommercial use, distribution, and reproduction in any medium, provided the original author(s) and the source are credited.

\section{REFERENCES}

1. Aaronson NK, Muller M, Cohen PD, et al. Translation, validation, and norming of the Dutch language version of the SF-36 Health Survey in community and chronic disease populations. J Clin Epidemiol. 1998;51:1055-68.

2. Benjamin EJ, Levy D, Vaziri SM, D’Agostino RB, Belanger AJ, Wolf PA. Independent risk factors for atrial fibrillation in a population-based cohort: the Framingham Heart Study. JAMA. 1994;271:840-4.

3. Jais P, Cauchemez B, Macle L, et al. Catheter ablation versus antiarrhythmic drugs for atrial fibrillation: the A4 study. Circulation. 2008;118:2498-505.

4. Benjamin EJ, Wolf PA, D'Agostino RB, et al. Impact of atrial fibrillation on the risk of death: the Framingham Heart Study. Circulation. 1998;98:946-52.

5. Wilber DJ, Pappone C, Neuzil P, et al. Comparison of antiarrhythmic drug therapy and radiofrequency catheter ablation in patients with paroxysmal atrial fibrillation: a randomized controlled trial. JAMA. 2010;303:333-40.

6. Reynolds MR, Walczak J, White SA, et al. Improvements in symptoms and quality of life in patients with paroxysmal atrial fibrillation treated with radiofrequency catheter ablation versus antiarrhythmic drugs. Circ Cardiovasc Qual Outcomes. 2010;3:615-23.

7. Wokhlu A, Monahan KH, Hodge DO, et al. Longterm quality of life after ablation of atrial fibrillation the impact of recurrence, symptom relief, and placebo effect. J Am Coll Cardiol. 2010;55:2308-16.

8. Weerasooriya R, Jais P, Hocini $M$, et al. Effect of catheter ablation on quality of life of patients with paroxysmal atrial fibrillation. Heart Rhythm. 2005;2:619-23.

9. Oral H, Pappone C, Chugh A, et al. Circumferential pulmonary-vein ablation for chronic atrial fibrillation. N Engl J Med. 2006;354:934-41.

10. Pappone C, Augello G, Sala S, et al. Randomized trial of circumferential pulmonary vein ablation versus antiarrhythmic drug therapy in paroxysmal atrial fibrillation. J Am Coll Cardiol. 2006;48:2340-7.

11. Forleo GB, Mantica M, De Luca L, et al. Catheter ablation of atrial fibrillation in patients with diabetes mellitus type 2: results from a randomized study comparing pulmonary vein isolation versus antiarrhythmic drug therapy. J Cardiovasc Electrophysiol. 2009;20:22-8.

12. Jenkins LS, Brodsky M, Schron E, et al. Quality of life in atrial fibrillation: the Atrial Fibrillation Follow-up Investigation of Rhythm Management (AFFIRM) study. Am Heart J. 2005;149:112-20.

13. Roy D, Talajic M, Nattel S, et al. Rhythm control versus rate control for atrial fibrillation and heart failure. N Engl J Med. 2008;358:2667-77.

14. Dorian P, Paquette M, Newman D, et al. Quality of life improves with treatment in the Canadian Trial of Atrial Fibrillation. Am Heart J. 2002;143:984-90. 